\title{
Paresthesia and forearm pain after phlebotomy due to medial antebrachial cutaneous nerve injury
}

\author{
Mahsa Asheghan*, Amidoddin Khatibi and Mohammad Taghi Holisaz
}

\begin{abstract}
Back ground: Although phlebotomy is a common procedure, there is limited information concerning to documented complications of venipuncture.

Case presentation: A 45 year old left- handed woman was refered for elecrodiagnostic study with dysesthesia and pain in left medial forearm. She noted these symptoms three weeks after phelebotomy. Electrodiagnostic study showed severe involvement of left side Medial Antebrachial Cutaneous nerve (MAC nerve).
\end{abstract}

Conclusion: Phelebotomy is a cause of MAC nerve injury. Electrodiagnostic testing can be helpful in evaluating cases of sensory disturbance after phlebotomy.

\section{Background}

The MAC nerve can be damaged by a number of iatrgenic causes. Phlebotomy is a rare cause of injury.

We present a case of phlebotomy-induced injury to the MAC nerve, in which the diagnosis was made using nerve conduction study. According to our knowledge, this is the first case in which electrodiagnostic studies were used to document venipuncture-related injury of the MAC nerve. The use of electrodiagnostic test for diagnosis of this type of injury, has only been reported one time for radial nerve and three for lateral antebrachial cutaneous nerve [1-4].

\section{Case presentation}

A 45 year left-handed woman was referred to electromyography clinic for electrodiagnostic study because of hypoesthesia over the medial aspect of left forearm. She complained of a shooting pain along with the onset of dysesthesias over there. She noted this complaint since three weeks ago after routine venipuncture. The patient had no history of polyneuropathy, chronic systemic disease or surgical intervention at the elbow. Physical examination showed normal inspection and muscles power but decreased sensation of pinprick and light

\footnotetext{
* Correspondence: mahsaasheghan@yahoo.com
}

Department of Physical Medicine and Rehabilitation, Baghyatollah Hospital, Baghyatollah University of Medical Sciences, Mollasadra Street, Tehran, Iran touch in anteromedial aspect of forearm. Electrodiagnostic study was performed on bilateral MAC nerves using routine technique [5]. The study revealed absence of sensory nerve action potential from the left MAC nerve, and normal in right side [Figure 1].

For confirmation the diagnosis, we tried several times with stimulation in various points in cubital fossa and with high stimulation current up to $45 \mathrm{~mA}$. All other nerves in left upper limb were normal in nerve conduction studies. The diagnosis was severe injury to left MAC nerve after phlebotomy. Unfortunately we could not follow the patient for further evaluation.

\section{Discussion}

The MAC nerve originates from the medial cord or rarely the lower trunk, and is derived from segments C8 and T1. This nerve is subcutaneous just proximal to the medial epicondyle and course along the medial aspect of the arm to provide cutaneous sensation to the medial forearm. Some sort of MAC nerve injury in literature includes steroid injection for medial epicondylitis, cubital tumor surgery, elbow arthroscopy, orthopedic surgery, tumor and routine venipuncture [6-12]. It is also caused more rarely by repeated minor trauma, soft tissue laceration and tuberculoid leprosy neuritis or subcutaneous lipoma [13-15]. Several reports of nerve injuries after phlebotomy included injury to lateral antebrachial 


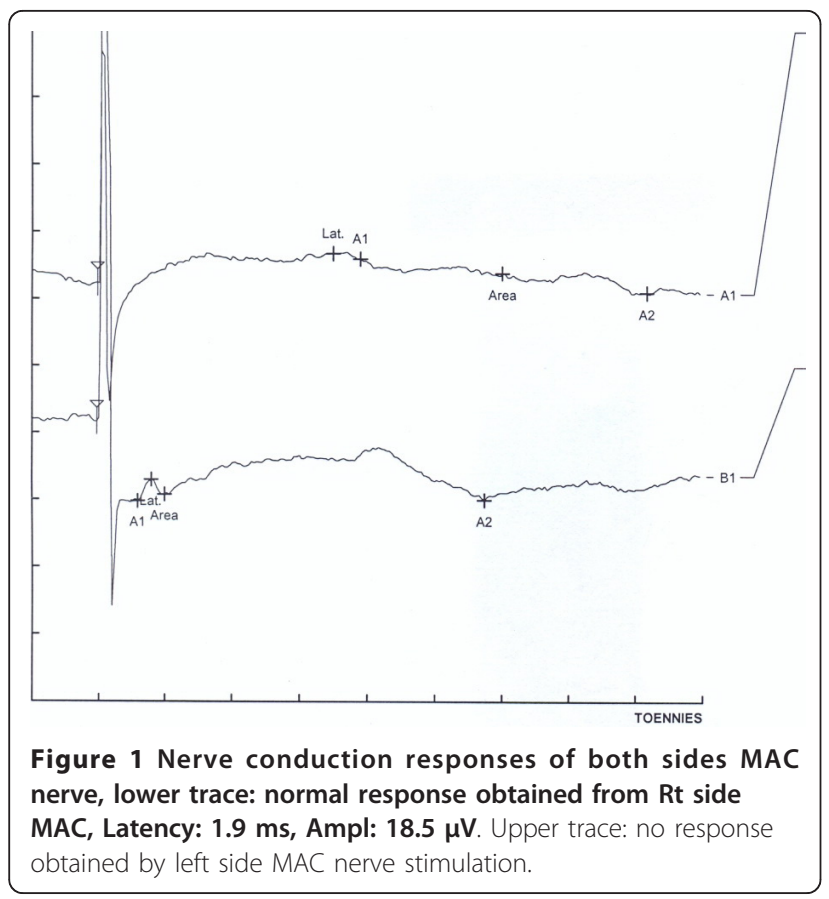

cutaneous nerve, MAC, radial, dorsal ulnar sensory branch in hand $[16,17]$. Because of superficial position of nerves in cubital fossa, these are susceptible to injury during phlebotomy especially where multiple attempts done. This is the first case in which electrodiagnostic studies were used to make the diagnosis of a direct injury of the MAC nerve as a result of phlebotomy.

MAC nerve injury may be undiagnosed, because the nerve is purely sensory and there is no motor abnormality. On the other hand, the electrophysiological studies of MAC nerve is not a part of routine upper extremity electrodiagnostic examinations. The clinician and the electromyographer should be aware of to this condition. In conclusion, MAC nerve injury should be taken into account for the differential diagnosis of the patients with complaints of pain and dysestesia in medial forearm and anteromedial aspect of the elbow. Electrodiagnostic study should be used for evaluation of patients with complaint of neurologic symptoms after phlebotomy to diagnose the location and severity of the injury.

\section{Consent}

Written informed consent was obtained from the patient for publication of this case report

\section{Authors' contributions}

MA carried out the electrodiagnosis studies. AK participated in the design of the study. MTH conceived of the study, and participated in its design and coordination. All authors read and approved the final manuscript.

\section{Competing interests}

The authors declare that they have no competing interests.
Received: 5 January 2011 Accepted: 6 September 2011

Published: 6 September 2011

\section{References}

1. Edwards WC, Fleming LL: Radial nerve palsy at the elbow following venipuncture-case report. J Hand Surgery [Am] 1981, 6:486-9.

2. Stitik TP, Foye PM, Nadler SF, Bruchman GO: Phlebotomy related lateral antebrachial cutaneous nerve injury-case report. Am J Phy Med Rehabil 2001, 80:230-4

3. Sander HW, Conigliari M, Masdeu JC: Antecubital phlebotomy complicated by lateral antebrachial cutaneous neuropathy. $N$ Engl J Med 1998, 339:2024.

4. Rayegani SM, Azadi A: Lateral antebrachial cutaneous nerve injury induced by phlebotomy. J Brachial Plex Peripher Nerve Inj 2007, 2:6.

5. Daneil Dumitru: Electrodiagnostic medicine. second. HANLEY \& BELFUS; 2002.

6. Richards RR, Regan WD: Medial epicondylitis caused by injury to the medial antebrachial cutaneous nerve: a case report. Can J Surg 1989, 32:366-7.

7. Horowitz SH: Peripheral nerve injury and causalgia secondary to routine venipuncture. Neurology 1994, 44:962-64.

8. Sarris I, Göbel F, Gainer M, Vardakas DG, Vogt MT, Sotereanos DG: Medial brachial and antebrachial cutaneous nerve injuries: Effect on outcome in revision cubital tunnel surgery. J Reconst Microsurg 2002, 18:665-70.

9. Lowe JB, Maggi SP, Mackinnon SE: The position of crossing branches of the medial antebrachial cutaneous nerve during cubital tunnel surgery in humans. Plast Reconstr Surg 2004, 114:692-96.

10. Stahl S, Rosenberg N: Surgical treatment of painful neuroma in medial antebrachial cutaneous nerve. Ann Plast Surg 2002, 48:154-60.

11. Kelly EW, Morrey BF, O'Driscoll SW: Complications of elbow arthroscopy. J Bone Joint Surg Am 2001, 83-A:25-348.

12. Chiu YN, Huang YL, Chang CW: Medial antebrachial cutaneous neuropathy: a case report. Electromyogr Clin Neurophysiol 2008, 48:125-7.

13. Chang CW, Ho SJ: Medial antebrachial cutaneous neuropathy. Case report Electromyogr Clin Neurophysiol 1988, 28:3-5.

14. Martins RS, Siqueira MG, Carvalho AAS: A case of isolated tuberculoid leprosy of antebrachial medial cutaneous nerve. Neurol Sci 2004 , 25:216-19

15. Seror P: Forearm pain secondary to compression of the medial antebrachial cutaneous nerve at the elbow. Arch Phys Med Rehabil 1993, 74:540-42

16. Yuan RT, Cohen MJ: Lateral antebrachial cutaneous nerve injury as a complication of phlebotomy. Plast Reconstr Surg 1985, 76:299-300.

17. Berry PR, Walls WE: Venipuncture nerve injuries. The Lancet 1977, 1236-7.

\section{doi:10.1186/1749-7221-6-5}

Cite this article as: Asheghan et al.: Paresthesia and forearm pain after phlebotomy due to medial antebrachial cutaneous nerve injury. Journal of Brachial Plexus and Peripheral Nerve Injury 2011 6:5.

\section{Submit your next manuscript to BioMed Central and take full advantage of:}

- Convenient online submission

- Thorough peer review

- No space constraints or color figure charges

- Immediate publication on acceptance

- Inclusion in PubMed, CAS, Scopus and Google Scholar

- Research which is freely available for redistribution 